Molecules 2005, 10, 1438-1445

\title{
molecules
}

ISSN 1420-3049

http://www.mdpi.org

\section{An Efficient Protocol for the Solid-phase Synthesis of Malondiamides}

\section{Markus M. Vögtle and Andreas L. Marzinzik*}

Novartis Institutes for BioMedical Research, WSJ-507, CH-4002 Basel, Switzerland; Fax: (+41) 613246589

* To whom correspondence should be addressed; E-mail: andreas.marzinzik@novartis.com

Received: 5 August 2005; in revised form: 18 October 2005 / Accepted: 20 October 2005 / Published: 31 December 2005

\begin{abstract}
A novel and straightforward solid-phase synthesis of malondiamides containing a free nitrogen has been developed. These intermediates, which can be directly obtained in good yield and purity, can be further derivatised. This approach can be used for the synthesis of large split-and-mix-libraries.
\end{abstract}

Keywords: Combinatorial chemistry - Solid-phase synthesis - Amides - Acylations Peptides.

\section{Introduction}

Recently we have published a short and efficient protocol for the solid-phase synthesis of malondiamides leading to products of the general structure 1 (Scheme 1) [1]. The compounds obtained by exploiting this protocol show, in general, druglike properties and can be viewed at as retro-inverso surrogates of small peptide fragments.

\section{Results and Discussion}

The preparation of the malondiamides 1 was performed with several preloaded resins (loading 0.30 $-0.85 \mathrm{mmol} / \mathrm{g}$ ) 2, substituted malonyl dichlorides $\mathbf{3}$ and a diverse set of amines $\mathbf{5}$. Among the amines used, a wide variety such as benzylamines, piperazines, and primary and secondary aliphatic amines could be reacted successfully. 


\section{Scheme 1}

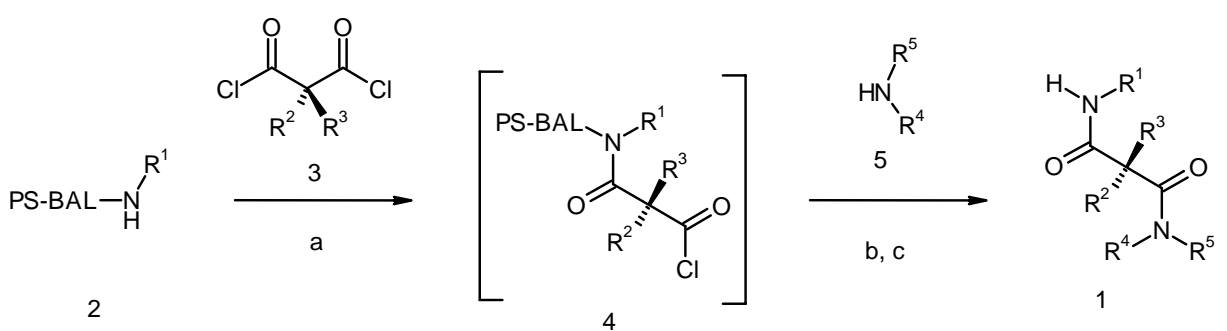

Reagents and conditions: (a) DCM/DIPEA 4:1, RT, $1 \mathrm{~h}$ - 12 h. (b) DCM/DIPEA 4:1, RT, 3h - 48 h. (c) $\mathrm{TFA}_{95 \%} / \mathrm{DCM} 1: 4$.

Only amines with a high steric demand, such as diisopropylamine and tert-butylmethylamine or anilines afforded no product within two days reaction time at room temperature as judged by LC-MS after acid mediated cleavage. Because we planned to exploit this chemistry for the synthesis of splitand-mix libraries, it was pivotal that the formation of side-products via crosslinking between two resin bound amines by one molecule of diacid dichloride could be excluded. To apply this efficient protocol for the construction of more complex structures and to introduce a further point of diversity, it was envisaged to react the polymer-bound acid chlorides with bifunctional amines, which could be further derivatised with established nitrogen decorating chemistries. However, the use of unprotected piperazine 5a (Scheme 2, $\left.\mathrm{R}^{2}=\mathrm{R}^{3}=\mathrm{CH}_{2} \mathrm{CH}_{3}, \mathrm{n}=1\right)$ or homopiperazine $5 \mathbf{b}(\mathrm{n}=2)$ gave only mixtures of the desired products 6 and the crosslinked bis-malonyl tetraamides 7 [2]. These products could easily be separated and isolated by normal- or reverse-phase chromatography, but precluded this approach from being applied in a split-and-mix synthesis. Larger excesses of reagents and higher concentrations or the use of resins with lower loadings $(<0.2 \mathrm{mmol} / \mathrm{g})$ did not significantly change the ratio of desired compounds to by-products.

\section{Scheme 2}
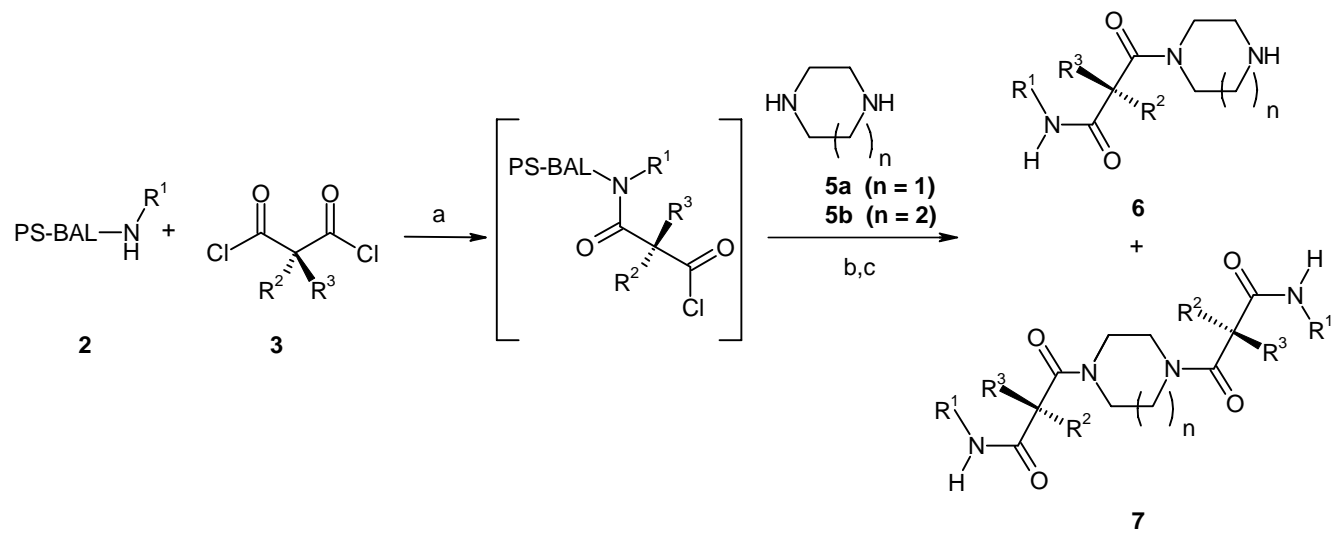

Reagents and conditions: (a) DCM/DIPEA 4:1, RT, $1 \mathrm{~h}-12$ h. (b) DCM/DIPEA 4:1, RT, 8 h - 16 h. (c) $\mathrm{TFA}_{95 \%} / \mathrm{DCM} 1: 4$. 


\section{Scheme 3}

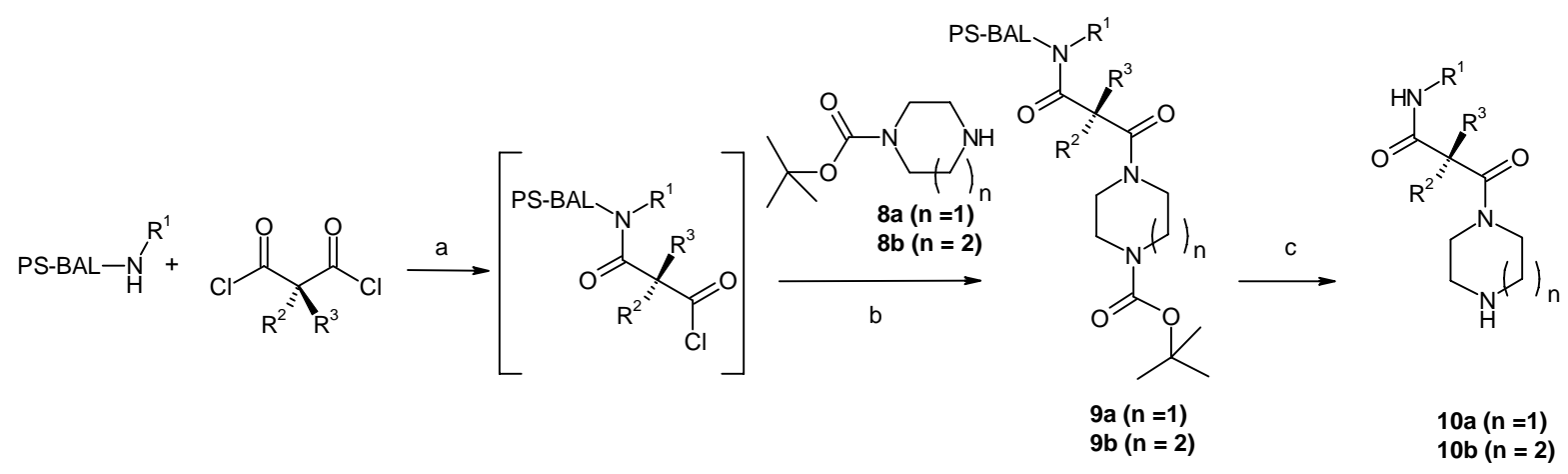

Reagents and conditions: (a) DCM/DIPEA 4:1, RT, $1 \mathrm{~h}$ - 12 h. (b) DCM/DIPEA 4:1, RT, 8 h - 16

h. (c) $\mathrm{TFA}_{95 \%} / \mathrm{DCM} 1: 4$.

Not surprisingly, a complete different outcome was found when the same reactions were performed with mono-Boc-piperazine and mono-Boc-homopiperzine, respectively. The single product obtained after acid mediated cleavage were the expected malondiamides with the tert-butoxy carbonyl protecting group smoothly cleaved (Scheme 3). During the studies to elaborate the scope and limitations of this protocol we have found that both, primary and secondary N'-Boc protected diamines, can successfully be acylated by the resin bound acid chloride (Table 1). TFA mediated cleavage yielded the free amines in good to excellent purity as judged by HPLC and NMR. On-bead deprotection of the N'-Boc moiety was performed by established procedures (TMS-triflate, lutidine). The only drawback of this methodology was the incompatability with some ether functionalities (especially aliphatic methoxy ones) on the backbone amide [3]. The free amines could then be decorated with established protocols such as sulfonylation (Table 2, entry 1-4)[4], acylation (Table 2, entry 5,9)[5], reductive amination (table 2, entry 6)[6], arylation (Table 2, entry 7)[7] and ureaformation[8] (Table 2, entry 8)[9].

Table 1. Solid-phase synthesis of malonamides,

\begin{tabular}{|c|c|c|c|c|c|c|}
\hline Entry & & Compound & $\mathbf{R}_{t}{ }^{a}$ & $\begin{array}{c}\text { Exact Mass } \\
\text { Formula }\end{array}$ & Mass & $\begin{array}{c}\text { Relative } \\
\text { Peak } \\
\text { Area(\%) }\end{array}$ \\
\hline 1 & 11 & & 3.05 & $\begin{array}{c}385.43 \\
\mathrm{C}_{19} \mathrm{H}_{26} \mathrm{~F}_{3} \mathrm{~N} \\
\mathrm{O}_{2} \\
\end{array}$ & 386.3 & 94 \\
\hline 2 & 12 & & 3.27 & $\begin{array}{c}329.45 \\
\mathrm{C}_{19} \mathrm{H}_{27} \mathrm{~N}_{3} \mathrm{O}_{2}\end{array}$ & 330.4 & 93 \\
\hline 3 & 13 & & 2.59 & $\begin{array}{c}390.49 \\
\mathrm{C}_{20} \mathrm{H}_{30} \mathrm{~N}_{4} \mathrm{O}_{4}\end{array}$ & 391.6 & 93 \\
\hline
\end{tabular}


Table 1. Cont.

\begin{tabular}{|l|l|l|l|l|l|l|}
\hline 4 & 14 & & 2.22 & 348.41 & 348.3 & 92 \\
\hline 5 & 15 &
\end{tabular}

(a) Retention time (minutes), column: Prontosil 120-3-C18, $4.3 \mathrm{~mm} \times 53 \mathrm{~mm} ; 3 \mu \mathrm{m} ; 1.5$ $\mathrm{mL} / \mathrm{min}$; 15 -min gradient from $100 \%$ aqueous media $(0.1 \% \mathrm{TFA})$ to $100 \% \mathrm{CH} 3 \mathrm{CN}(0.1 \% \mathrm{TFA})$.

(b) LC-MS: EI-positive mode (c) Relative peak area by HPLC based on UV absorption at 214 $\mathrm{nm}$.

Experimental conditions were refined to reach after cleavage suitable purity for biological testing without further purification. It was found crucial for this approach that the first acylation of the backbone-nitrogen must be complete or otherwise by-products are formed. Purity and identity were checked by LC-MS and HPLC. Representative compounds were subjected to spectroscopic characterization, in addition, some of the products were crystalline and have been submitted to x-ray analysis to obtain experimental data about (solid-state) conformations (e.g. Table 2, entry 3). A more extensive exploitation of this protocol's diversity potential was achieved by repetition of the procedure. (Table 2, entry 9) As an example 27 could be obtained by acidic cleavage in moderate purity after deprotection, subsequent acylation with dimethylmalonyl dichloride and trapping with 1(4-methoxy-phenyl)-piperazine. The impurities found in this case could be assigned to fragments derived from incomplete acylation and partial loss of the methoxy ether moiety during the Boc deprotection process.

\section{Scheme 4}

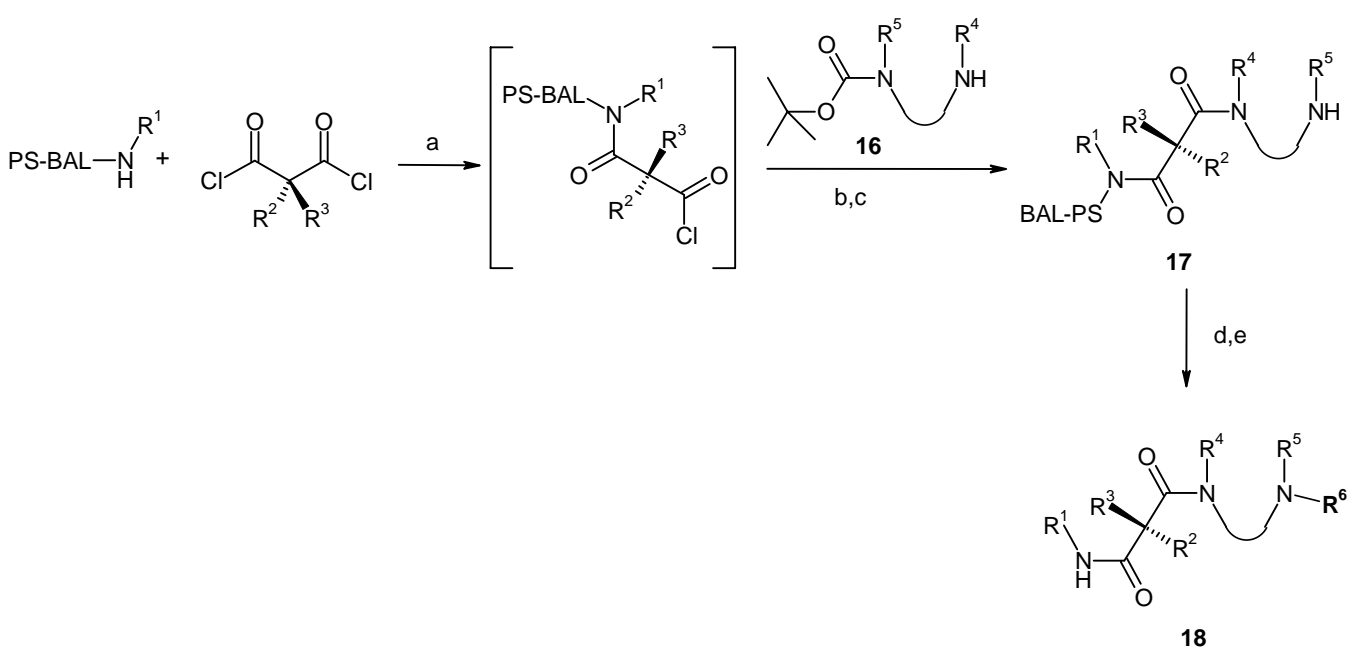

Reagents and conditions: (a) DCM/DIPEA 4:1, RT, $1 \mathrm{~h}-12 \mathrm{~h}$. (b) mono-Boc-diamine, DCM/DIPEA 4:1, RT, 8 h - 16 h. (c) TMS-triflate, lutidine, DCM, RT, 2 x 30 min. (d) NDerivatisation (e) $\mathrm{TFA}_{95 \%} / \mathrm{DCM}$ 1:4. 
Table 2. Solid-phase synthesis of malonamides.

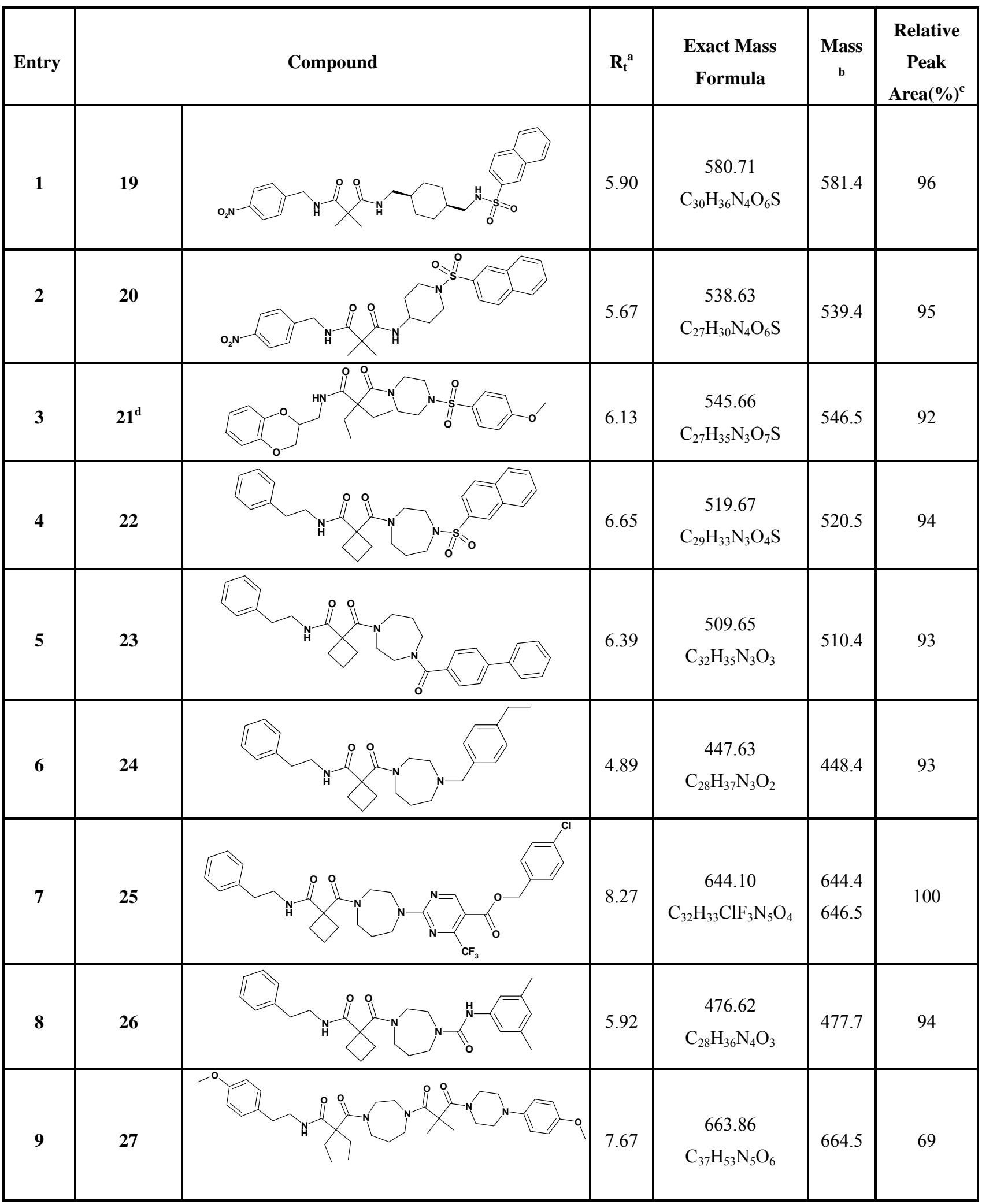

(a) Retention time (minutes), column: Prontosil 120-3-C18, $4.3 \mathrm{~mm} \times 53 \mathrm{~mm} ; 3 \mu \mathrm{m} ; 1.5 \mathrm{~mL} / \mathrm{min} ; 15$-min gradient from $100 \%$ aqueous media (0.1\% TFA) to $100 \% \mathrm{CH}_{3} \mathrm{CN}(0.1 \%$ TFA). (b) LC-MS: EI-positive mode (c) Relative peak area by HPLC based on UV absorption at $214 \mathrm{~nm}$ (d) The characterization of this compound could be supported by $\mathrm{x}$-ray crystallography. 
The validity of this protocol was exemplified by the preparation of a small split-and-and-mix library (Figure 1). Five preloaded resins (loading $0.30-0.85 \mathrm{mmol} / \mathrm{g}$ ) were thoroughly mixed and reacted with dimethyl malonyl dichloride, carefully washed and quenched with Boc-piperazine. The resin was deprotected and acylated with 4-nitrobenzoyl chloride. LC-MS and HPLC analysis of the cleaved mixture showed good purity ( $>96 \%$ of the total UV-trace area at $214 \mathrm{~nm}$ ) and identity.

Figure 1. LC-MS (EI-positive mode) of mixture of 30a-e

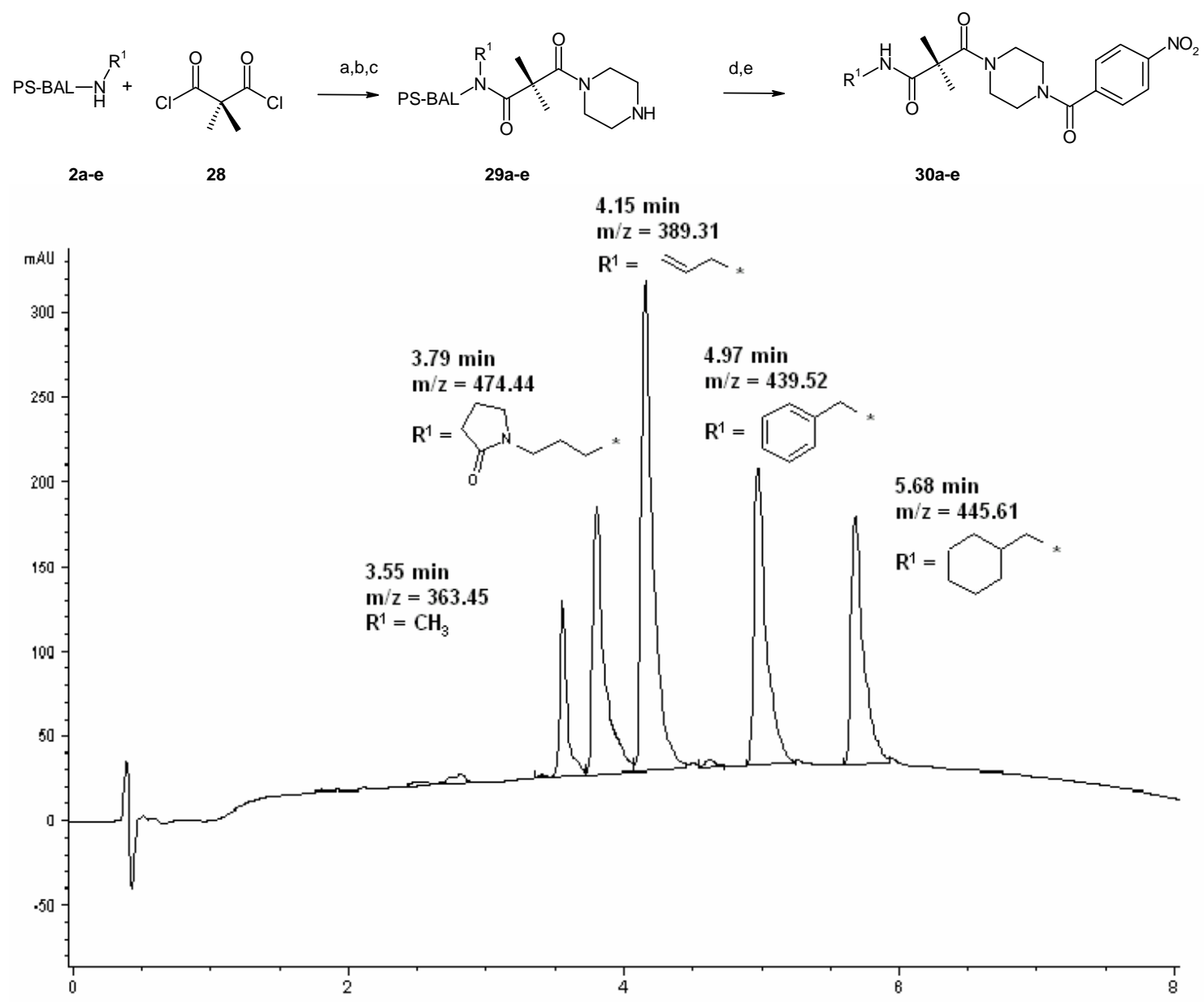

Reagents and conditions: (a) DCM/DIPEA 4:1, RT, 6 h. (b) Boc-piperazine, DCM/DIPEA 4:1, RT, 16 h. (c) 1 M TMSOTf, 1.5 M 2,6-1utidine, DCM, RT, 2 x 30 min. (d) 4nitrobenzoylchloride, DMAP, DCM, RT, 6h. (e) TFA $95 \%$ DCM 1:4.

\section{Conclusions}

The approach presented here is a robust and efficient protocol for the synthesis of the title compounds. The preparation of the malondiamides was performed with a variety of resins and several diamines. The polymer bound intermediates can be further reacted with established nitrogen decorating techniques to introduce further diversity. 


\section{Acknowledgments}

We thank Werner Breitenstein, Philipp Grosche and Jürg Zimmermann for helpful discussions, Trixi Wagner for x-ray analyses and Susanne Osswald for help with NMR-characterization.

\section{Experimental}

${ }^{1} \mathrm{H}-\mathrm{NMR}$ and ${ }^{13} \mathrm{C}-\mathrm{NMR}$ were run at $400 \mathrm{MHz}$ and $125 \mathrm{MHz}$, respectively, on a Bruker AM 400 spectrometer $\left({ }^{1} \mathrm{H}-\mathrm{NMR}\right)$ using TMS as internal standard. The spectra were recorded at room temperature. Compounds that form diastereomeric rotamers can give rise to complex spectra. LC-MS spectra were recorded on an Agilent HP1100 LC / Waters ZQ-2000 system (Prontosil 120-3-C18) at 70 $\mathrm{eV}$.

\section{General Procedure}

BAL-resin (2, $200 \mathrm{mg})$ was washed with 5:1 DCM/DIPEA, then the dialkyl malonyl dichloride (3, 10 equivalents) was added in 4:1 DCM/DIPEA ( $3 \mathrm{~mL})$ and the mixture was shaken for $12 \mathrm{~h}$. The resin was washed three times with 4:1 DCM/DIPEA, then the mono-Boc diamine (10 equivalents) in 4:1 DCM/DIPEA ( $3 \mathrm{~mL})$ was added and shaken at RT overnight. The resin was filtered off and then washed with DCM, DMA and finally $\mathrm{MeOH}$. BOC deprotection was performed by shaking the resin twice with $1 \mathrm{M}$ TMSOTf ( $3 \mathrm{~mL})$ and $1.5 \mathrm{M}$ 2,6-1utidine in DCM ( 2 x $30 \mathrm{~min})$. The resin was washed several times with DCM, DMA and finally $\mathrm{MeOH}$. The resin was subjected to $\mathrm{N}$-derivatisation and then washed again (DCM, DMA, MeOH). The resin was dried and then treated twice with TFA 95\%/DCM (1:4). Evaporation of the solvents yielded the products. Selected examples were purified by flash chromatography for analytical reasons.

2-Ethyl-2-(piperazine-1-carbonyl)- $N$-(4-trifluoromethyl-benzyl)-butyramide (11, Table 1, entry 1): Colorless oil, contains TFA. No further purification. ${ }^{1} \mathrm{H}-\mathrm{NMR}\left(\mathrm{CD}_{3} \mathrm{OD}\right): \delta=7.69(2 \mathrm{H}, \mathrm{d}, \mathrm{J}=9.1 \mathrm{~Hz})$, 7.55 (2 H, d, J = 9.1 Hz), 4.35 (2 H, s), $3.50-3.70$ (4 H, s, broad), 2.80 - 2.00 (4 H, s, broad), 1.90 (2 $\mathrm{H}, \mathrm{m}), 1.75(2 \mathrm{H}, \mathrm{m}), 0.70(6 \mathrm{H}, \mathrm{m}) ;{ }^{13} \mathrm{C}-\mathrm{NMR}\left(\mathrm{CD}_{3} \mathrm{OD}\right): \delta=175.6,173.8,145.1,131.5,131.2$, $130.9,130.5(q), 130.0,126.9,123.0,119.1,116.2,113.3(q), 60.4,44.4,44.2,38.9,26.9,9.1$.

N-(2,3-Dihydro-benzo[1,4] dioxin-2-ylmethyl)-2-ethyl-2-[4-(4-methoxy-benzenesulfonyl)-piperazine-1carbonyl]-butyramide (21, Table 2, entry 3): Colorless crystals, 92\% crude purity (HPLC-214 nm), 93\% crude yield, 76\% isolated yield after flash chromatography. $\mathrm{R}_{\mathrm{f}}=0.22$ (1:1 hexane/ethylacetate); $\lambda_{\max }=242 \mathrm{~nm} ;{ }^{1} \mathrm{H}-\mathrm{NMR}\left(\mathrm{DMSO}_{6}\right): \delta=7.90(\mathrm{~m}, 1 \mathrm{H}), 7.56(2 \mathrm{H}, \mathrm{d}, \mathrm{J}=6.9), 7.05(2 \mathrm{H}, \mathrm{d}, \mathrm{J}=6.9)$, 6.77 - 6.90 (4 H, m), $4.22(1 \mathrm{H}, \mathrm{m}), 4.12(1 \mathrm{H}, \mathrm{m}), 3.87(1 \mathrm{H}, \mathrm{m}), 3.79(3 \mathrm{H}, \mathrm{s}), 3.40$ - 3.53 (4 H, s), $3.17-3.24(2 \mathrm{H}, \mathrm{m}), 2.70-2.85(4 \mathrm{H}, \mathrm{s}), 1.60-1.80(4 \mathrm{H}, \mathrm{m}), 0.61(6 \mathrm{H}, \mathrm{t}) ;{ }^{13} \mathrm{C}-\mathrm{NMR}\left(\mathrm{DMSO}_{6}\right)$ : $\delta=172.8,169.11,162.9,142.9,142.6,129.83,125.9,121.5,121.3,117.1,116.9,114.5,71.48,71.1$, $65.7,56.6,55.7,45.5,24.5,8.00$.

2-[4-(1-Phenethylcarbamoyl-cyclobutanecarbonyl)-[1,4]diazepan-1-yl]-4-trifluoromethyl-pyrimidine5 carboxylic acid 4-chloro-benzyl ester (25, Table 2, entry 7): Colorless crystals, $100 \%$ crude purity 
(HPLC-214 nm), 88\% crude yield, 82\% isolated yield after flash chromatography. Mixture of rotamers at room temperature. $\mathrm{R}_{\mathrm{f}}=0.45$ (2:1 hexane/ethylacetate); $\lambda_{\max }=281 \mathrm{~nm} ;{ }^{1} \mathrm{H}-\mathrm{NMR}\left(\mathrm{DMSO}-\mathrm{D}_{6}\right): \delta=$ $8.99(1 \mathrm{H}, \mathrm{s}), 7.03$ - $7.48(9 \mathrm{H}, \mathrm{m}), 5.28(2 \mathrm{H}, \mathrm{m}), 3.52$ - $3.95(6 \mathrm{H}, \mathrm{m}), 3.08$ - $3.25(4 \mathrm{H}, \mathrm{m}), 2.75(2 \mathrm{H}$, $\mathrm{m}), 2.30-2.42$ (4 H, m), $1.61-1.70(4 \mathrm{H}, \mathrm{m}) ;{ }^{13} \mathrm{C}$ NMR $\left(\mathrm{DMSO}_{6}\right): \delta=182.3,177.7,170.9,170.7$, $163.0,162.6$ (q), 153.9, 139.4, 134.7, 132.8, 130.0, 128.5, 128.2, 126.2, 119.5 (q), 109.8, 65.8, 55.0, 53.33, 47.8, 46.0, 45.7, 49.3, 34.8, 28.8, 27.3, 25.1, 15.0.

4-(1-Phenethylcarbamoyl-cyclobutanecarbonyl)-[1,4]diazepane-1-carboxylic acid (3,5-dimethylphenyl) amide (26, Table 2, entry 8): Colorless crystals, 94\% crude purity (HPLC-214 nm), 78\% crude yield, 71\% isolated yield after flash chromatography. Mixture of rotamers at room temperature. $\mathrm{R}_{\mathrm{f}}=$ 0.24 (2:1 hexane/ethylacetate); $\lambda_{\max }=244 \mathrm{~nm} ;{ }^{1} \mathrm{H}-\mathrm{NMR}\left(\mathrm{DMSO}_{6}\right): \delta=7.52(2 \mathrm{H}, \mathrm{m}), 7.08-7.27(5$ $\mathrm{H}, \mathrm{m}), 6.56(1 \mathrm{H}, \mathrm{d}), 3.15-3.57(10 \mathrm{H}, \mathrm{m}), 2.70(3 \mathrm{H}, \mathrm{m}), 2.30(3 \mathrm{H}, \mathrm{m}), 2.19(2 \mathrm{H}, \mathrm{m}), 1.74(2 \mathrm{H}, \mathrm{m})$, $1.64(4 \mathrm{H}, \mathrm{m}), 1.53(2 \mathrm{H}, \mathrm{m}) ;{ }^{13} \mathrm{C}-\mathrm{NMR}\left(\mathrm{DMSO}_{6}\right): \delta=171.5,170.7,154.8,140.4,140.2,139.44$, $137.0,128.7,128.3,126.0,123.4,123.2,117.8,54.0,53.3,47.5,47.2,46.9,46.0,40.5,34.9,29.1$, $26.3,21.1,15.4$.

\section{References and Notes}

[1] Vögtle, M. M.; Marzinzik, A. L. A Short and Efficient Protocol for the Solid-Phase Synthesis of Retro-Inverso Surrogates, Synlett 2005, 496 - 500.

[2] The ratio was determined by HPLC at $254 \mathrm{~nm}$ and $214 \mathrm{~nm}$ and ${ }^{1} \mathrm{H}-\mathrm{NMR}$.

[3] Zhang, A. J.; Russel, D. H.; Zhu, J. P; Burgess, K. A method for removal of N-BOC protecting groups from substrates on TFA-sensitive resins, Tetrahedron Lett. 1998, 7439 -7442.

[4] Bolton, G. L.; Hodges, J. C.; Rubin, J. R. Solid phase synthesis of fused bicyclic amino acid derivatives via intramolecular Pauson-Khand cyclization: Versatile scaffolds for combinatorial chemistry, Tetrahedron 1997, 6611 - 6634.

[5] Bicknell, A. J.; Hird, N. W. Synthesis of a highly functionalized rigid template by solid phase azomethine ylide cycloaddition, Biorg. Med. Chem. Lett. 1996, 2441 - 2444.

[6] (a) Green, J. Solid Phase Synthesis of Lavendustin A and Analogs, J. Org. Chem. 1995, 4287 4290; (b) Devraj, R.; Cushman, M. A Versatile Solid Phase Synthesis of Lavendustin A and Certain Biologically Active Analogs, J. Org. Chem. 1996, 9368 - 9373.

[7] Reaction conditions: 10 eq. 2-chloro-4-trifluoromethyl-pyrimidine-5-carboxylic acid p-chlorobenzyl ester, DMA/DIPEA 4:1, 24 h, RT; TFA $95 \% / D C M ~ 1: 4$.

[8] Lee, S. H.; Chung, S. H.; Lee, Y. S. Preparation of resin-bound ketimines via transimination and its application in the synthesis of hydantoin libraries, Tetrahedron Lett. 1998, 9469 - 9472.

[9] Zaragoza Dörwald, F.; Organic Synthesis on Solid Phase; Wiley-VCH: Weinheim, 2000 and references therein.

Sample availability: Contact the authors

(C) 2005 by MDPI (http://www.mdpi.org). Reproduction is permitted for noncommercial purposes. 